\title{
Critical Reflective Practice as an Approach to Developing Transformative Living-theory
}

\author{
Sadruddin Bahadur Qutoshi
}

\begin{abstract}
This reflective paper aims to provide an opportunity to the readership in the field of transformative education in order to engage them with reflective practices as professional development approach. In academia, writing reflective papers, using multi-paradigmatic research design, for readers believing in post/positivist views is a challenging task. However, innovative editors of journals encourage to create new knowledge through un/conventional approaches. I used Jack Whitehead's paper (i.e., the review of my doctoral studyCreating living-educational-theory: A journey towards transformative teacher education in Pakistan) and my own reflections as lived experiences to carry out this study. Moreover, I employed reflexivity as an approach to meaning making to serve the purpose of data analysis in this paper. The key findings of this study show that Jack Whitehead skillfully captures key learning outcomes of the doctoral study and synthesized some deep insights very precisely. He created a space for future researchers especially action researches and self-study practitioners to think about how to engage with multi-epistemic approaches in order to experience transformative learning. It is recommended to encourage reflective writings on un/conventional studies to develop a clear understanding of the existing state of teacher education and nature of the journey of transformative teacher education in the academia.
\end{abstract}

Keywords: reflective practice, critical reflection, transformative research, teacher education, professional development

\section{Introduction}

This paper uses reflective writing as an approach to critical engagement to make meaning of the text and context (Silva, 2018) of the research paper written by Jack Whitehead, the father of living educational theories along with my own reflections on my doctoral study. In his paper, he came up with an innovative approach to research and to capture the central themes of author's doctoral study on 'a transformative teacher education programme for Pakistan and a living-educational-theory'. In order to create new knowledge from both key insights shared by Whitehead (2016) and the areas needed to elaborate so as to convey contextual meaning. Critical reflections serve as methodological basis for this paper to write. Though, unconventional writers face multiple challenges to satisfy conventional reviewers to understand such kind of approaches to research, it is gaining momentum in both transformative research and living theory community.

Thus, this paper is an attempt to enable wider readership to realize the importance of reflective practices. It will also enable them to develop a clear understanding of the study on transformative teacher education and living-theory perspective. To this end, a comprehensive view needs to be presented about text and contexts through reflections. Here, in this section, before providing reflective views, I would like to provide a contextual background of the study to the readers.

Teacher education in the context of Pakistan has gone through different phases in the form of policy reforms (i.e., developing new policies to improve practices) and implementation outcomes (e.g., its effects on practices) since its independence in 1947. As a nation, by embracing an education inherited from British colonial state, we believe in a system of education that is based on a 'technical interest of education' (Habermas, 1972). Such an education appears to be linked with a view of educational leadership as dictating (Qutoshi, 2016), curriculum as reproduction and curriculum as textbooks. Moreover, the metaphor of teaching as informing, assessment as an add-on activity (Luitel, 2009), and education research as positivism. This narrowly conceived view of education could not lead the nation to progress in the right direction.

However, from time to time political leadership came to realize this inherited issue that could be addressed through reforms in education. To overcome such kind of chronic issues in the system of education many efforts have been made in the history of Pakistan. These reformative efforts somehow created a space for some improvement in teacher education. For example, in the form of review of curriculum and its development (i.e., bringing some changes in content and approaches to its implementation through teaching learning activities at classroom level). However, reforms in education, for many reasons, could not fully address such culturally embedded issues of educative endeavours in Pakistan.

One of the obvious reasons of such failures could be the donor driven agendas of reforms in education in the country. Unfortunately, these reforms have been 
un/willingly influenced by some donor-driven agendas to improve state of education in the country rather than focusing on the real issues to fix. As a result, such efforts could not give desirable or intended outcomes of the reforms. Probably, one of the reasons behind such kind of influence is the power of donors' interests in projects like improving state of education in developing countries like Pakistan.

In such a situation, the political leadership appears to serve as new colonial masters with a Western Modern Worldview (the leaders who serve the interest of donor's along their own personal interest compromise over national interest). Thus these leaders embraced such kind of opportunities to do something in the name of improving education without giving due importance to practices at grassroots level. Resultantly, such reforms in teacher education could not facilitate teachers and learners to bring improvements at classroom level.

However, these reforms to some extent paved the way to move towards a kind of practical interest of education (Habermas, 1972) and could highlight a theoretical view of John Dewey's concept of education as an experience. Such a reformative view of improvement in state of education could hardly focus on a theoretical view of curriculum as an experience and social reformation, and instruction as learner centered. These reformative developments appear to be a good but not sufficient to address the challenges of 21 st century teaching and learning.

Thus, the issues of teacher education without engaging both policy makers and implementers with critical reflections as unconventional approaches to knowing seems unproductive. Because engaging practitioners (especially teachers) with reflective writing on reforms and their effects on improving teaching learning practices help to develop culturally responsive pedagogies (Brockett, 2015). Thus keeping this view in mind, I embraced an unconventional approach to research as professional development engagement during my doctoral study. This critical engagement not only enabled me to critique the state of teacher education in Pakistan but also helped me to create a space for further deliberations and reflections to learn deep insights of our educative endeavours.

Jack Whitehead argued that in the context of Pakistan, employing an unconventional approach to research, some critical questions at three levels were rightly addressed by Sadruddin in his doctoral study (Qutoshi, 2016). These levels are informing (a very traditional approach to education, which is termed as technical interest of education), reforming (somehow improved version of education as a result of reforms that is a kind of practical interest of education), and finally transforming, a liberating view of education or an emancipatory interest of education (Habermas, 1972). Moreover, Jack also acknowledged how author engaged critically with the issues of traditional teacher education, limitations of reformative education, and power of a transformative view of education for Pakistan.

\section{Findings and Discussion}

Whitehead (2016) interestingly engages readership by explaining approaches that used to create a transformative living-educational-theory. He further acknowledged the power of employing multi-epistemic lenses such as 'reflexivity, inclusive logics, multiple genres and multiple ways of knowing' (Whitehead, 2016, p.1) 'self' and 'others' (sociocultural and socio-pedagogical others) in the context of Pakistan. While reflecting on the originality of the study and the power of soulful inquiry as multiple ways of knowing, Jack Whitehead proficiently developed a strong link with de Sousa Santo's (2014) idea of 'ecologies of knowledges' and concept of Rayner's 'natural inclusion'. This shows Whitehead (2016)'s creativity and his highly intellectual engagement to make meaning of texts and contexts (Silva, 2018) to explain the nature of transformative living-theory approach to professional development.

Moreover, he appears to conclude the idea that how critical-creative epistemologies as unconventional approaches to knowing can empower researchers to seek contextual sustainable solutions of culturally embedded issues of education for transforming perceptions, beliefs, assumptions and practices. For example, he rightly argued that reflective practice is 'at the heart of the generation of this transformative teacher education programme and living-educational-theory' that 'is the experience and motivational power of 'soulful-inquiry" (Whitehead, 2016, p.1). Perhaps, this view highlights the importance of a soulful-inquiry that uses critical self-reflections to challenge taken for granted ways of being and becoming as a teacher educator.

This view further raises the question 'in what ways such innovative inquiries enable researchers as transformative educators'. Because a transformative educator and/or a researcher is working not only for bringing improvement in the existing conditions of teaching and learning but also for creating conditions for sustainable development of both self and others in the field of teacher education. This very view of knowing transformative learners appears to be an opportunity for readers to reflect on their lifeworld, and get engage with writing critical-self reflections so as to experience transformation.

Moreover, Whitehead (2016) excellently came up with the originality of the study as a reaction to oppressive modes of knowing and knowledge generation as an approach to education and research. These practices have deeply embedded in the roots of the colonial state, and having its influence in the educational system of Pakistan. He further concluded key findings of the thesis in the form of five transformative visions for teacher education and research practices in Pakistan:

1. A living-educational-theory of inclusive coleadership with embodied values of intention of doing good for others, humility for humanity, care of self and others with ecological consciousness, love and peace; 2 . The use of a metaphor of montage in conceiving a liberating view of curriculum; 3 . Critical-creative pedagogies for 
an empowering view of education; 4. A holistic view of authentic-developmental assessment; 5. An innovativeintegral view of transformative research' (Whitehead, 2016, p .1).

This part of Whitehead' paper appears to be one of the strengths that explicitly highlights the importance of living theory as an approach to improve practices in teacher education. Because these five themes can serve as an eye opener for readers about the transformative teacher education, a holistic view of teacher education program in Pakistan that currently legged behind.

Moreover, Jack appears to offer readers as teachers and teacher educators to reflect on a transformative teacher education program in their own educational context. In so doing, readers can start writing reflections on their beliefs and practices of teaching and learning, and can offer culturally relevant and sustainable solutions to the contextual problems in their practices. This view of critical engagement of practitioners can lead them to experience a transformative education for sustainable development. Because it is the transformative view of education that enables teacher, teacher educator and students to engage themselves with critical-reflections on self and others with a specific lens for continuous professional development rather than just critiquing on beliefs and practices in the field of teacher education. . I think, engaging with critical reflective practices in the field of teacher education is a powerful way to professional development that ultimately leads towards sustainable development. Here sustainable development means to develop a habit of mind to critically reflect on self (and socio-pedagogical others) continuously to improve practices in the field of teacher education.

Probably, engaging with such an approach to professional development demands to develop clear understanding of cultural context of teacher education and its implications. In the context of Whitehead' paper, a section-wise review of the thesis would be more explanatory in terms of stories and contextual situations to provide a clear picture of how to create a transformative living theory. In so doing, the readers/researchers (action researchers in the field of teacher education) could challenge their own held assumptions, deeply rooted perspectives and could develop new perspectives (Mezirow, 1978, 2012) that can bring transformation in their views, beliefs and actions. Because transformation means a deeper level change that could lead a paradigm shift in thinking, believing and doing as a process of continuous professional development. Thus transformation is linked with the concept of continuous improvement through critical reflections, and that is more sustainable than a surface level change embedded in a reformative agenda.

Moreover, yet another important view of Habermasian view (1972) of holistic approach to teacher education with technical, practical and emancipatory interests, and goals of education with specific reference to informing, reforming and transforming view needs to be provided. Perhaps, without providing a clear view of these critical aspects of the study a reader cannot make better sense of the existing state of teacher education, and envisioning a transformative view of education. Therefore, this reflective paper argues that a section wise review could be an effective approach to engage readers to develop their better understanding about the nature of the study and its contributions.

For example, in section one of the doctoral study, the author came up with the idea of creating a space for self as an unconventional researcher (without rejecting conventional approaches to research) in the field of teacher education. In so doing, he appears to justify his positionality by embracing an autoethnographic soulful-inquiry within multiparadigmatic research design space. In his doctoral study, he explains how critical-creative approaches can better facilitate researchers in knowing a phenomenon under discussion at 'highdeep' level (Saldana, 2015), and engage learners with a liberating view of education.

In section two, the thesis offers a reflective view on how informing as dictating leadership and reforming as communicating leadership could not empower educational practitioners as leaders in the context of educational institutions in Pakistan. Thus, as a result of the limited views of leadership as dictating and communicating open a space and enabled the author to envision a transformative leadership as basis for transforming self, organizations and societies. Such a notion of transformative leadership as cobecoming and co-evolving (Qutoshi, 2016) addressed in this section is embedded within an emancipatory way of knowing culturally responsive leadership practices.

The reflections on the section offer readers to develop clear understanding of their role as a teacher, teacher educator and researcher to make meaning of their own leadership styles as dictating, communicating and transforming. In other words it is important to provide a picture, from within the study, to practitioners by addressing questions like 'how they lead their students and what could be the implications of their roles as leaders'.

Similarly, in section three the thesis came up with traditional, modern and postmodern images and metaphors of curriculum which would be more interesting for readers to develop an understanding of a diverse range of curriculum images. Because such views on metaphors and images of curriculum can help readers to make better sense of Bal Chandra Luitel's call to embrace a transformative curriculum as montage (Luitel \& Taylor, 2008). In order to develop a strong relationship of such a view of curriculum images with pedagogies and assessment practices, section four and five provide views on informing, reforming and transforming approaches to teaching and assessment practices respectively. In so doing, readers can develop their understanding of the complex relationship of assessment practices with both curriculum images and teaching approaches. Because to improve learning of learners, teachers need to understand the importance of curriculum images and use of critical-creative pedagogies.

In so doing, the thesis offers researchers especially educational practitioners to reflect on their beliefs and practices of teaching and learning in their own cultural contexts. Because using an innovative and inclusive way to reflect on 'self' and 'others' can open one's eyes about 
a liberating or an emancipatory view of pedagogical approaches and assessment practices. Probably, sharing these insights with readers could enable them to think about self to become professional teachers as reflective practitioners.

In section six, the thesis offers a critical reflective view of Newtonian Science Research and its limitations. In so doing, such reflections enable researchers and readers to think about embracing unconventional approaches to research in order to cultivate transformative research practices. Perhaps, this could be a challenging view for conventional researchers yet could be a call for embracing an emancipatory view of research that is much needed for the 21 st century researchers as knowledge creators.

Finally, in section seven, the thesis offers a culmination of a transformative journey of 'self' as a teacher educator and researcher. In this section, the researcher established foundation through autobiographical excavations of lived experiences in the form of early days of schooling till his doctoral studies. Building on a historiographical view of creating knowledge the study presents a proposal for initiating a transformative teacher education program for Pakistan.

Thus, the absence of such a section-wise review on the critical epistemological take woven in the whole thesis appears to be very difficult for the readers to understand the transformative research journey of the author. Whereas a section-wise review would be more helpful for readers to understand complex issues discussed in the thesis, and build the linkages with the running thread of the key concepts highlighted.

Likewise, if Jack could provide a brief picture of the researcher' identity that may help readers to make better sense of how can they (readers/researchers) engage with a transformative living theory accounts of their life-worlds. For example, how early educational life in a village setting and later on getting an opportunity to study at a doctoral level by employ multi-epistemic lenses as ways of knowing self and others enabled the author to challenge Western Modern World views. Sharing such critical moments in the life of a doctoral researcher could help readers to think about their own interest in the field of transformative research for personal and professional development.

This paper asserts that sharing such an identity of the researcher, and his engagement with the concept of 'glocalizaion' (Luitel, 2009), a call to think out of the box solutions to a contextual problems of teacher education and research, would help practitioners to find solutions at their own ends. In so doing, such reflection would help readers to think about how the author could use local wisdom traditions (without excluding Western wisdom traditions) in order to create a transformative livingeducational-theory. Moreover, engaging readers with reflective practices would serve as an approach to selfprofessional development in the field of teacher education rather relying on conventional approaches to teachers training and development.

If Jack could discuss about researchers' identity construction as a professional development approach to research that might help readers to improve self and others. For instance, they could reflect on how the researcher experienced through a phenomenological journey of self as a conventional researcher to a more unconventional and critical-self-reflective practitioner as transformative researcher. In so doing, the readers would get an idea of working towards a transformative journey in their own cultural context.

\section{Conclusion}

This reflective paper is an attempt to create new knowledge through unconventional approaches to research as a professional development activity. It is embedded within critical reflective practice as an approach to write on self, socio-cultural, and socio-pedagogical others. In so doing, the paper opens windows of multi-epistemic engagement for personal professional development of writer as critically self-reflective practitioners in the field of teacher education and research. The exposure of researcher to employ unconventional approaches to research, such as multi-paradigmatic research design space, empowered him to use multiple 'ecologies of knowledge's' to disrupt and challenge taken for granted views and ways of knowing. Thus, by accepting self as a change agent' (Whitehead, 2016) the author could create his living theory of a transformative teacher education in the context of Pakistan.

Probably, recommending readers and authors as researchers to embrace innovative yet complex ways of knowing would be a motivating call for developing transformative-living-theorists around the globe (especially societies influenced by the western hegemonic thinking). Such writers as autoethnographer (Pinar, 2014, 2015), action researcher as living theorist (Whitehead, 1989, 2016), unconventional researchers as transformative learners (Luitel \& Taylor, 2012) and reflective-practitioners as professional development agents (Qutoshi, 2016) can help self and others as professional educators in the field of teacher education and research.

\section{Reference}

Brockett, R. G. (2015). Teaching adults: A practical guide for new teachers. San Francisco, CA: Jossey-Bass.

de Sousa Santos, B. (2014). Epistemologies of the South: Justice against Epistemicide. London; Paradigm Publishers.

Habermas, J. (1972). Knowledge and human interest (2nd Ed.). London, England: Heinemann.

Luitel, B. C. (2009). Culture, worldview and transformative philosophy of mathematics education in Nepal: A cultural-philosophical inquiry (Unpublished doctoral thesis). Curtin University, Perth, Australia.

Luitel, B. C., \& Taylor, P. C. (2008, Jan). Globalization, ecological consciousness and curriculum as montage: A vision for culturally contextualized mathematics education. Paper presented at the 16th Annual Conference of the Southern African Association for Mathematics, Science and Technology Education 
(SAARMSTE), Maseru, Lesotho.

Mezirow, J. (1978). Perspective transformation. Adult Education, 28, 100-110.

Mezirow, J. (2012). Learning to think like an adult: Core concepts of transformation theory. In E. W. Taylor \& P. Cranton (Eds.), The handbook of transformative learning: Theory research and practice (pp. 73-96). San Francisco, CA: Jossey-Bass.

Pinar, W. F. (2014). (Ed.). The international handbook of curriculum research. New York, NY: Routledge.

Pinar, W. F. (2015). Educational experience as lived. New York, NY: Routledge.

Saldana, J. (2015). Thinking qualitatively: Method of mind. Washington, DC: Sage.

Whitehead, J. (2016). Review of Sadruddin Bahadur Qutoshi's Doctoral Thesis, 'Creating livingeducational-theory: A journey towards transformative teacher education in Pakistan'.' Educational Journal of Living Theories, 9 (2), 107-109.

Whitehead, J. (1989). Creating a living-theory from questions of the kind, 'how do I improve my practice?' Cambridge Journal of Education, 19(1), 41-52.

Qutoshi, Sadruddin Bahadur $\mathrm{PhD}$ is working at the Karakorum International University as an Assistant Professor since 2008. He is coordinating the Centre for Training and Research on ECD at Faculty of Education. Before that, his two most recent full-time positions were as a Social Protection Coordinator and Gender Focal Person at UNDP, Pakistan, and immediately before that as a Principal, Metroville Community School Karachi. He graduated from Karachi University (B. Sc. \& MA-IR), University of London (MA-Edu \& Int. Dev) and Kathmandu University (Ph.D. in Education). His research interests and publications have focused on a wide range of issues related to cultural knowing, education, reforms in education, leadership, leading learning organizations, and transformative education and research for sustainable development etc. He is member of many review/editorial committees of inter/national Journals. He is currently supporting a range of work by community organizations on gender and quality education. He has worked in educational institutions within and abroad for over 15 years.

Email: subeditor.jer@uoch.edu.pk 